\title{
Alunos com deficiência física: a compreensão dos professores de Educação Física sobre a acessibilidade nos espaços de prática para as aulas
}

\author{
Luciana Erina Palma* \\ Sofia Wolker Manta**
}

\section{Resumo}

No âmbito das Políticas Educacionais, uma série de transformações vem ocorrendo desde as décadas de 1980-1990, no que diz respeito à inclusão de aluno com deficiência na rede regular de ensino. O estudo teve por objetivo analisar a compreensão dos professores de Educação Física e Séries Iniciais sobre a participação do aluno com deficiência física em aulas de Educação Física e a acessibilidade dos espaços de prática. Os professores participantes são de uma Escola Pública da Rede Regular de Ensino de uma cidade do Rio Grande do Sul. O instrumento utilizado para a coleta de dados foi uma entrevista semiestruturada com roteiro preestabelecido aos professores de Educação Física e aos professores de Séries Iniciais que ministravam aulas para turmas com inclusão de alunos com deficiência física. Por meio da análise dos dados nas entrevistas com as professoras, identificou-se que os espaços de prática das aulas de Educação Física não possuíam acesso nem a acessibilidade que garantissem a segurança e autonomia do aluno com deficiência física (DF), porém, estes alunos não deixavam de participar das aulas de Educação Física. Pode-se perceber, ainda, as barreiras atitudinais que o aluno com DF enfrenta no cotidiano da Escola e que precisam ser, urgentemente, eliminadas para que a inclusão desses alunos ocorra de forma participativa e livre de preconceitos. Por fim, é importante que, a partir de uma ação conjunta com toda a comunidade escolar, os espaços estejam cada vez mais acessíveis para serem utilizados por uma gama maior de pessoas.

Palavras-chave: Educação Física; Acessibilidade; Deficiência física.

\footnotetext{
* Professora Doutora, Departamento de Métodos e Técnicas Desportivas, Centro de Educação Física e Desportos, Universidade Federal de Santa Maria (UFSM), Santa Maria, Rio Grande do Sul, Brasil.

** Professora de Educação Física, Universidade Federal de Santa Maria (UFSM), Santa Maria, Rio Grande do Sul, Brasil.
} 


\title{
Luciana Erina Palma - Sofia Wolker Manta
}

\section{Students with Disabilities: the understanding of physical education teachers on the Accessibility to places of practice for classes}

\begin{abstract}
Within the scope of Educational Policies, a series of transformations has been occurring since the 80s and 90s regarding the inclusion of students with disabilities in the regular school system. The study aimed to analyze both the understanding of physical education teachers in the Initial Series about the participation of students with disabilities in physical education classes and accessibility of the spaces for practice. The teachers participating in the study are from a regular Public School system of Rio Grande do Sul. The instrument used for data collection was a semi-structured interview with a pre-established script to physical education teachers and teachers of Initial Series who taught classes with the inclusion of students with Disabilities. Through the analysis of data from the interviews with the teachers it was identified that the spaces for the practice of physical education classes did not have access or accessibility to ensure the safety and independence for students with physical disabilities (FD), but these students did not fail to participate in physical education classes. One can still see the attitudinal barriers that students with FD face in everyday school, and it urgently needs to be removed so that the inclusion of these students takes place in a participatory manner and free from prejudices. Finally, it is important from a joint action with the whole school community, spaces are becoming increasingly available for use by a wider range of people.
\end{abstract}

Keywords: Physical education; Accessibility; Disabilities.

\section{Introdução}

No âmbito das Políticas Educacionais, uma série de transformações vem ocorrendo desde as décadas de 1980-1990 no que diz respeito à inclusão do aluno com deficiência na Rede Regular de Ensino. Primeiramente um modelo Integrativo, no qual Sassaki (2005) aponta que o mérito desta proposta estava no seu forte apelo contra a exclusão e a segregação das pessoas com deficiência. Porém, o mesmo autor coloca que era de responsabilidade da pessoa com deficiência se adaptar ao meio, sem nenhuma modificação por parte da sociedade, exigindo pouco no sentido de modificação de atitudes, espaços e/ou práticas sociais.

O modelo da Inclusão surge como um novo ideário de educação mundial. Diferentemente da integração, este modelo parte do pressuposto de que todas as crianças e jovens, independente de deficiência, têm direito de estudarem juntos.

A inclusão de alunos com deficiência na rede regular de ensino não é meramente assegurar sua matrícula na escola, mas também fornecer subsídios 
necessários para seu aprendizado e autonomia, ou seja, garantia também de acessibilidade.

A acessibilidade passa a fazer parte do cenário educacional, no instante em que o direito de ir e vir com autonomia torna-se elemento importantíssimo para auxiliar na inclusão escolar e social (TANAKA, 2006). No entanto, para que este processo inclusivo se efetive, é necessário planejar e melhorar a acessibilidade arquitetônica nas escolas, para proporcionar condições de acesso das pessoas com deficiência física e/ou mobilidade reduzida a todos seus ambientes ou compartimentos (FREITAS et al., 2008).

Para Manzini (2006), a acessibilidade significa "algo que pode ser observado, implementado, medido e avaliado" ou, ainda, como forma de criar condições de acessibilidade para que as pessoas tenham acesso aos locais e/ ou a determinadas situações. Para fins de acessibilidade, considera-se barreira qualquer entrave ou obstáculo que limite ou impeça o acesso, a liberdade de movimento, a circulação com segurança e a possibilidade de as pessoas se comunicarem ou terem acesso à informação (BRASIL, 2005).

A importância da acessibilidade e a eliminação de barreiras arquitetônicas é um ponto crucial para favorecer a inclusão dos alunos com deficiência física em todos os ambientes da escola, inclusive nos ambientes de prática das aulas de Educação Física.

Pensar em Educação Física Escolar é também refletir sobre as potencialidades e possibilidades de movimento de cada aluno, sem priorizar a sua deficiência e/ou suas limitações.

É importante que os(as) professores(as) de Educação Física, assim como os(as) professores(as) de Educação Infantil, como é o caso dos(as) professores(as) de Séries Iniciais, profissionais estes que trabalham em seus currículos a relação do corpo e do movimento, conheçam as características de cada aluno para, assim, oportunizar as vivências motoras (SAYÃO, 2002).

As barreiras arquitetônicas são grandes dificuldades que o aluno com deficiência física enfrenta para a prática de atividade física e/ou de participação em aulas de Educação Física (DIEHL, 2006). Este é um dos aspectos visíveis de exclusão, sem considerar, ainda, as barreiras atitudinais e sociais que as pessoas com deficiência em geral enfrentam perante a sociedade.

O conceito de deficiência física que irá permear o estudo vai ao encontro de Diehl (2006, p. 100), como sendo de várias origens:

origem cerebral (paralisia cerebral e traumatismo crânio-encefálico); origem medular (poliomelite, espinha bífida, lesões medulares degenerativas, traumatismos 
medulares); origem muscular (distrofia muscular progressiva de Duchenne); origem ósseo-articular (malformações, amputação). Além disso, as pessoas com Deficiência Física apresentam formas variadas de como o uso de instrumentos ou aparelhos e até mesmo a não-utilização de recursos.

É importante que os(as) professores(as) de Educação Física e os(as) professores(as) de Séries Iniciais tenham o conhecimento sobre a deficiência dos alunos, além do reconhecimento sobre as potencialidades de movimento que o aluno pode desenvolver e aprimorar nas aulas de Educação Física, independente de suas limitações físicas e/ ou sensoriais.

Buscou-se, com este estudo, analisar a compreensão dos(as) professores(as) de Educação Física e dos(as) professores(as) de Séries Iniciais sobre acessibilidade dos ambientes de prática das aulas de Educação Física para a participação de alunos com deficiência física.

\section{Metodologia}

O grupo de estudo foi composto por: uma Escola Pública Regular da Rede Estadual de uma cidade do Rio Grande do Sul, que possuíam alunos com deficiência física matriculados e que estivessem inseridos nas aulas de Educação Física; a participação de uma professora de Educação Física e duas professoras de Séries Iniciais que ministravam aulas em turma que havia alunos com Deficiência Física da mesma Escola.

O instrumento utilizado para a coleta de dados foi uma entrevista semiestruturada, com roteiro preestabelecido às professoras participantes, sendo este baseado em Barba (2005).

A participação das professoras de Séries Iniciais justifica-se pelo fato de que alunos com deficiência estão nas Séries Iniciais e as professoras que trabalham Educação Física nessas Séries (período de $1^{\circ}$ ao $4^{\circ}$ ano ou série) possuem a formação em Magistério e/ou Pedagogia. Por isso, devido a esta realidade presente nas Escolas Estaduais do Rio Grande do Sul, surge a necessidade de considerar, no estudo, as diferentes áreas que ministram aulas de Educação Física nas Escolas.

Como duas professoras de Séries Iniciais participaram deste estudo, na apresentação dos resultados, elas serão identificadas como: professora $\mathbf{A}$ e professora B, e como houve somente a participação de uma professora de Educação Física, esta será mencionada desta forma.

\section{Resultados e discussão}

A partir da entrevista semiestruturada com uma professora de Educação Física e duas professoras de Séries Iniciais, foram criadas três categorias 
Alunos com deficiência física: a compreensão dos professores de Educação Física sobre a acessibilidade nos espaços de prática para as aulas

de análise: A) Formação do Profissional e o aluno com DF na turma; B) Os espaços de prática e a participação do aluno com DF nas aulas e C) Entendimento sobre o conceito de acessibilidade e a acessibilidade nos espaços de convivência do aluno.

\section{a) Formação do Profissional e o aluno com DF na turma}

Segundo relato da professora de Educação Física, seu tempo de formação é de 12 anos na área e há três anos trabalha na Escola com alunos com deficiência em turmas regulares, porém, em outras situações fora do ambiente escolar, já teve o contato com pessoas com deficiência. A turma em que ministrava a aula era a $5^{a}$ série (Ensino Fundamental) da EJA (Educação de Jovens e Adultos) e o aluno que tinha DF apresentava limitação de movimento na coluna cervical e nos membros superiores, que eram encurtados. A professora ao ser questionada sobre a interação do aluno com a turma e vice-versa relatou que todos interagiam com o colega.

Segundo a professora, mesmo já tendo a experiência com alunos com deficiência "a gente fica com um pouco de medo se fosse uma deficiência muito severa". No entanto, esse "medo" que a professora de Educação Física relata, é natural quando ainda não se teve a oportunidade de trabalhar com alunos com deficiências mais comprometidas, pois o contato irá permitir que conheça e reconheça a individualidade de cada aluno e suas potencialidades e habilidades para a prática nas aulas de Educação Física, desfazendo o estigma de que limitação é impossibilidade de movimento.

Corroborando com a discussão, Diehl (2006) afirma que a importância em proporcionar a prática de atividade aos alunos com deficiência é uma maneira de fornecer condições para aumentar seu repertório de movimento e o desenvolvimento de todo seu potencial, assim como é também um meio facilitador de interação social.

A professora A é formada em Magistério, Português e Literatura e tem especialização em Gestão Escolar. Há sete anos trabalha na Rede Estadual e há três anos trabalha em turmas regulares com alunos com deficiência. A turma em que ministrava aula era uma $4^{\mathrm{a}}$ série, e seu aluno que tinha DF apresentava dificuldades de locomoção nos membros inferiores, mas deslocava-se sozinho.

A professora $\mathbf{A}$ ao ser questionada sobre a interação do aluno com a turma e vice-versa, relata que o aluno com DF é muito carinhoso e educado com todos, mas, infelizmente, a turma não aceita o colega com DF e diz: "A impressão que eu tenho é que eles ignoram o colega, tanto nas atividades de Educação Física como na sala de aula, apenas dois ou três me ajudam com ele, mas somente quando eu peço". Neste caso, a professora deixa claro as barreiras atitudinais que os alunos com DF enfrentam em seu cotidiano na Escola. Segundo Guedes (2007), as barreiras atitudinais são vistas sob forma de discrimi- 


\section{Luciana Erina Palma - Sofia Wolker Manta}

nação, esquecimento, ignorância e preconceito que acaba fortalecendo o mecanismo de exclusão dos alunos com Deficiência na Escola. Duarte e Cohen (2006) salientam que, muitas vezes, essas barreiras atitudinais estão presentes nos próprios pais das crianças sem deficiência, no momento em que evitam a socialização e o encontro dos seus filhos com a diversidade física e social.

Além disso, a eliminação de barreiras atitudinais será possível a partir de um trabalho que, segundo Duek e Naujorks (2006, p. 38), menciona

cabe ao professor propiciar condições de ensino adequadas para um número expressivo de alunos, sensivelmente diferentes uns dos outros, o que permitirá constituir não só numa troca de conhecimentos, mas também uma troca de idéias, de valores e de princípios de vida.

Com isso, na percepção de uma escola inclusiva, a diversidade deve ser a norma e não mais a exceção (SMEHA; SEMINOTTI, 2008, p. 02). Mantoan (apud SMEHA; SEMINOTTI, 2008) apresenta o sentido da escola inclusiva em que o professor precisa estar atento à singularidade de cada aluno, promovendo a integração entre todos sem intencionar a tão almejada turma "homogênea".

Já a professora B tem vinte e oito (28) anos de formação em Magistério, Pedagogia e Teologia, atuando diretamente nas Escolas e garante que sempre teve o contato com alunos com deficiência. A turma em que ela ministrava aula era o $2^{\circ}$ ano do Ensino Fundamental, seu aluno que tinha DF apresentava comprometimentos motores nos membros inferiores, locomovia-se em cadeiras de rodas, tinha pouca amplitude na movimentação dos membros superiores, incontinência urinária, apresentava problemas neurológicos e salivava constantemente, necessitando de auxílio. Diferentemente do relato da professora A, esta turma interagia bem com o colega com DF, e a professora B comenta: "não preciso nem pedir auxílio para os colegas, a iniciativa parte da própria turma, tanto em sala de aula como nos momentos da Educação Física". E diz ainda: "a turma já se acostumou com ele, porque estão juntos desde o ano passado, então sabem das limitações e do que ele precisa".

De certa forma, o relato desta professora comprova que o contato e a convivência permitem a descoberta e o reconhecimento de que cada indivíduo é único e que, independente de limitações físicas, o importante é identificar e aprimorar as potencialidades de movimentos do aluno com DF. Percebe-se, ainda,que um dos grandes objetivos e méritos da educação inclusiva é oportunizar a convivência com a diversidade humana, aprender a conviver com as diferenças de cada pessoa, respeitando suas limitações e desenvolvendo suas potencialidades e habilidades.

Segundo Sassaki (2005), a inclusão é um processo mundial irreversível, pois é a partir de práticas baseadas na valorização da diversidade humana, no 
Alunos com deficiência física: a compreensão dos professores de Educação Física sobre a acessibilidade nos espaços de prática para as aulas

respeito pelas diferenças individuais que se abrem caminhos para a construção de uma sociedade verdadeiramente para todos.

\section{b) Os espaços de prática e a participação do aluno com DF nas aulas}

A professora de Educação Física relata que seu aluno com DF participava integralmente das aulas. O aluno chegava sozinho em todos os espaços de prática, as quais ocorriam duas vezes na semana e geralmente eram realizadas nas quadras cobertas ou na sala de ginástica, no segundo andar da escola.

A professora A revela que as aulas ocorriam duas vezes na semana, no espaço de área livre e na pracinha ou, em caso de chuva, as atividades eram desenvolvidas em sala de aula. Ao ser questionada sobre o deslocamento do aluno com DF aos espaços de prática, mencionou que o aluno chegava sozinho, porém necessitava de auxílio para subir as rampas, pois as mesmas não possuíam corrimão, dificultando o equilíbrio e prejudicando sua segurança e autonomia.

Segundo a professora $\mathrm{A}$, nos espaços de área livre, o desnivelamento do terreno era perigoso, aumentando os riscos de quedas. E relatou: "tenho muito medo que ele caia, então eu passo correndo atrás dele a aula toda". Percebe-se, nesta afirmação da professora, que o acesso aos espaços de prática da Educação Física e a não acessibilidade nos próprios espaços faz com que a professora limitasse a participação do aluno com DF nas atividades de Educação Física, em decorrência da superproteção, impedindo, desta forma, a experimentação e a vivência do aluno nos espaços da escola.

Todavia é importante analisar esta superproteção da professora, considerada como uma barreira atitudinal, pois fica à parte no momento em que é responsabilidade da escola fornecer aos alunos segurança em seus ambientes, ou como também à própria responsabilidade da professora em assegurar e zelar pela integridade física do aluno nas atividades propostas em aula.

Corroborando com esta discussão, Tuan (apud DUARTE; COHEN, 2006, p. 4) argumenta que,

a questão da experiência espacial por parte dos alunos com Deficiência nos espaços da Escola, permite que o aluno desenvolva cognitivamente, a partir da percepção e da apreensão do espaço, o laço afetivo com a Escola, sentindo-se parte dela e identificando-se com o ambiente em que estudam.

Entretanto, a experiência espacial vem a ratificar a importância dos espaços escolares estarem acessíveis para que o aluno com deficiência possa interagir e ter acesso a todos os espaços de prática das aulas de Educação 
Física, de maneira que possa desenvolver o seu comportamento motor, nos domínios cognitivos, afetivos, sociais e motores.

A professora B menciona que devido ao comprometimento motor do aluno com DF tornava-se complicado o acesso aos espaços de prática em que eram desenvolvidas as aulas de Educação Física, que, no caso, ocorriam ou na quadra coberta, ou na sala de ginástica. Todo o deslocamento era feito pelo próprio aluno em sua cadeira de rodas, porém, ao chegar próximo às quadras, a professora precisava auxiliá-lo para ultrapassar as barreiras arquitetônicas (dificuldade de acesso as quadras devido a um desnivelamento do terreno nas laterais da quadra) e, dependendo da atividade, o aluno permanecia na cadeira de rodas ou a cadeira ficava em um canto na quadra.

O mesmo ocorria quando a aula era na sala de ginástica, localizada no segundo andar da escola, sendo necessário o mesmo procedimento, carregálo para subir as escadas, ficando a cadeira de rodas na sala de aula. A professora relata que mesmo com todas essas barreiras arquitetônicas enfrentadas diariamente pelo aluno, ele não deixava de participar das aulas de Educação Física, e ressalta: "Ele adora quando na aula tem música".

No entanto, mesmo com as identificações das barreiras arquitetônicas pelas próprias professoras entrevistadas, a participação dos alunos com DF nas aulas de Educação Física está sendo efetivada, pelo menos em suas falas, pois, neste estudo, as aulas práticas não foram observadas.

\section{c) Entendimento sobre o conceito de acessibilidade e a acessibilidade} nos espaços de convivência do aluno

A professora de Educação Física entende a acessibilidade como sendo "As condições para chegar a um espaço, o que teria de obstáculos para chegar, além das relações interpessoais". Em relação aos espaços de convivência, essa mesma professora ressaltou que o seu aluno tinha bastante autonomia na locomoção, porém, reconhecia os vários empecilhos que os alunos em cadeiras de rodas enfrentavam nos ambientes de aulas de Educação Física e na própria escola. $O$ ideal de acessibilidade seria a construção de rampas para o acesso às quadras, além do próprio conhecimento do professor em trabalhar com alunos com deficiência.

Além disso, quando a professora menciona a formação acadêmica para o trabalho com alunos com deficiência, ou até mesmo a falta de experiência, pode-se considerar estes fatores como limitantes para a participação do aluno com DF nas aulas, caracterizando como fatores disseminadores de barreiras atitudinais. Pois do que adiantaria um local acessível se o professor não consegue fazer uso dele para favorecer a participação do aluno com DF nas aulas práticas de Educação Física ou até mesmo em atividade em sala de aula? 
Para a professora A, a acessibilidade é entendida como sendo: "O local onde o aluno possa desenvolver as capacidades motoras sem riscos". No entanto, a acessibilidade nos espaços de prática não garante que os riscos de quedas sejam evitados nas aulas de Educação Física, o risco é existente independente da acessibilidade, o que esta virá a proporcionar é o acesso ao local e as condições arquitetônicas mínimas para usufruto e permanência no local de qualquer usuário.

O ideal de acessibilidade salientado pela professora $\mathbf{A}$ é a necessidade de um maior suporte de materiais adaptados para o aprendizado do aluno, assim como o auxílio de um estagiário que pudesse acompanhar a turma enquanto ela acompanhasse o aluno com DF e também um melhor conhecimento sobre o trabalho com alunos com deficiência.

A falta de conhecimento para o trabalho com aluno com DF são apontados por ambas as professoras mencionadas anteriormente, porém é preciso questionar se esta falta de conhecimento é decorrente da inexistência de disciplinas nos cursos de formação em que abordem o conhecimento no trabalho com alunos com deficiência; ou se é devido à falta de experiência e contato com esses alunos; ou devido à falta de tempo em razão da exigência da carga horária do professor; ou, ainda, se foi em razão de a escola não oferecer cursos de formação continuada tratando sobre a Inclusão de alunos com deficiências.

De fato, o conhecimento do professor para o trabalho com alunos com DF vai além dos limites das barreiras arquitetônicas. Carmo (apud LIMA; PALMA, 2006) destaca que a não preparação dos currículos acadêmicos da Educação Física para o trabalho com alunos com e sem deficiência simultaneamente, pode ser fator limitante para a participação dos alunos nas aulas.

De acordo com Loro et al. (2008), a possibilidade de capacitação coletiva dos professores em exercício pode ser vista como um dos elementos fundamentais para um ensino de qualidade, por apresentar uma possibilidade de aprendizagem contextualizada e um momento de discussões acerca de propostas alternativas para as soluções pedagógicas.

A professora B considera a acessibilidade como "Uma possibilidade de acesso na locomoção até um ambiente, assim como de permanência em relação à segurança do local", o que vem a ser diferente de "sem riscos", mencionado pela professora $\mathbf{A}$.

Contudo, a professora $\mathbf{B}$ foi a que apresentou um entendimento mais amplo sobre acessibilidade, além de identificar as barreiras arquitetônicas enfrentadas cotidianamente pelo aluno com DF, acrescentou sugestões para reformas nos espaços e nos ambientes que são mais frequentados pela turma. No entanto, este entendimento sobre o ideal de acessibilidade pode ser em decorrência do tempo de convívio com alunos com deficiência em aula, de forma que 


\section{Luciana Erina Palma - Sofia Wolker Manta}

a leva a ter uma maior percepção das barreiras arquitetônicas enfrentadas pelos alunos com DF nos ambientes da escola e a identificação de suas maiores necessidades.

A eliminação das barreiras arquitetônicas nos espaços de práticas das aulas de Educação Física não garante a total participação do aluno com DF, se o professor que ministra as aulas não reconhecer ou não valorizar cada aluno como indivíduo único, criando alternativas e adaptações para que todos frequentem as aulas de forma igualitária.

\section{Considerações finais}

Pode-se perceber que a Inclusão de alunos com DF nas aulas de Educação Física ainda pode parecer um estigma para muitos professores e colegas de turma, pois, infelizmente, as barreiras atitudinais precisam ser eliminadas para que a inclusão desses alunos ocorra de forma participativa e livre de preconceitos. Em contrapartida, alguns professores lutam e se dedicam para que essa inclusão seja verdadeiramente um direito de todos, principalmente para o aluno com DF.

No entanto, as barreiras arquitetônicas na escola e nos ambientes de prática das aulas de Educação Física dificultam a autonomia e a liberdade na mobilidade dos alunos com DF e usuários de cadeiras de rodas nos ambientes escolares. Como é o caso da quadra de esporte, que não há acessibilidade para a cadeira de rodas, assim como a sala de ginástica, que é localizada no segundo piso da escola e o acesso a ela se dá somente por meio de escadas. Essas barreiras, segundo relatos das professoras, não impossibilitam a participação desses alunos nas aulas de Educação Física, pois há o auxílio tanto das professoras, como dos colegas para o acesso aos locais de prática, porém, impossibilita a autonomia do aluno de ir e vir.

É importante que os professores tenham essa sensibilidade em identificar as barreiras arquitetônicas que impeçam e/ou dificultam a participação do aluno com DF nas aulas, pois é uma maneira de solicitar à escola e aos responsáveis as devidas adaptações dos locais, para que os espaços estejam cada vez mais acessíveis a uma gama maior de pessoas. É importante também que os professores disseminem práticas e atitudes positivas perante a inclusão de alunos com deficiência, com a finalidade de combater as atitudes discriminatórias e valorizar a diferença e a heterogeneidade do grupo, de forma que essas ações conjuntas venham a contribuir com o direito ao acesso, assim como à eliminação de barreiras arquitetônicas, atitudinais, de informação e até mesmo as barreiras de formação profissional. 
Alunos com deficiência física: a compreensão dos professores de Educação Física sobre a acessibilidade nos espaços de prática para as aulas

\section{Referências}

BRASIL. Coordenadoria Nacional para a integração da Pessoa Portadora de Deficiência. Acessibilidade- Brasília: Secretaria Especial dos Direitos Humanos, 2005.

DIEHL, R. M. Jogando com as diferenças: jogos para crianças e jovens com deficiência. São Paulo: Phorte, 2006.

DUARTE, C. R. de S.; COHEN, R. Proposta de metodologia de avaliação da acessibilidade aos espaços de ensino fundamental. In: Anais NUTUAU, 2006: Demandas sociais, inovações tecnológicas e a cidade. São Paulo: USP, 2006.

DUEK, V. P.; NAUJORKS M. I. Inclusão e autoconceito: reflexões sobre a formação de professores. Revista Educação, Santa Maria, 2006, v. 31, n. 01, p. 35-52.

FREITAS, L. P. T. et al. Barreiras arquitetônicas: as limitações do direito de ir e vir dos alunos com deficiência física da Escola Agrotécnica Federal de Iguatu/ Campus I. In: CONGRESSO DE PESQUISAE INOVAÇÃO DA REDE NORTE E NORDESTE DE EDUCAÇÃO TECNOLÓGICA, 3., 2008, Fortaleza- CE. Anais... Disponível em: <http://www.intv.cefetce.br/connepi/viewpaper.php?id=1607>Acesso em: 31 mar.2009.

GUEDES, L. C. Barreiras atitudinais nas instituições de ensino superior: questão de educação e empregabilidade. Dissertação (Mestrado em Educação)-Universidade Federal de Pernambuco, Ceará, 2007, 271 p.

LIMA, M. D. de; PALMA, L. E. Reflexões acerca dos (des)caminhos da educação física na perspectiva do paradigma da educação inclusiva. In: REZER, R. (Org.). O fenômeno esportivo: ensaios críticos reflexivos. Chapecó: Argos, 2006, p. 131-144.

LORO, A. P. et al. A formação contínua dos professores de Educação Física da rede pública de ensino. Revista Educação, Santa Maria, v. 33, n. 2, p. 281-292, maio/ago. 2008 .Disponível em: <http://www.ufsm.br/revistaeducacao>. Acesso em: 28 set. 2009.

MANZINI, E.J. (Org.). Inclusão e acessibilidade. Marília, SP: ABPEE, 2006.

SASSAKI, R. K. Inclusão: o paradigma do século 21. Inclusão-Revista da Educação Especial, Brasília, out. 2005, v. 1, n. 1, p. 19-23.

SAYÃO, D. T. Corpo e movimento: notas para problematizar algumas questões relacionadas à educação infantil e à Educação Física. Rev. Bras. Cienc. Esporte, Campinas, v. 23, n. 2, p. 55-67, jan. 2002;

SMEHA, L. N.; SEMINOTTI N. Educação inclusiva: perspectivas da diferença no grupo de alunos. Santa Maria, v. 33, n. 2, p. 305-322, maio/ago. 2008 educação. Disponível em: <http://www.ufsm.br/revistaeducacao>. Acesso em: 29 set. 2009. 


\section{Luciana Erina Palma - Sofia Wolker Manta}

TANAKA, E. D. O. Acessibilidade: um dos caminhos para auxiliar na inclusão. Revista Brasileira de Educação Especial, Marília, jan./abr. 2006, v. 12, n.1, p. 139-142.

\section{Correspondência}

Luciana Erina Palma - Centro de Educação Física e Desportos: Campus Universidade Federal de Santa Maria, CEP 97105-900, n. 51, Núcleo de Estudos e Apoio da Educação Física Adaptada (NAEEFA). Santa Maria, Rio Grande do Sul, Brasil.

E-mail: luepalma@yahoo.com.br

Recebido em 30 de dezembro de 2009

Aprovado em 29 de maio de 2010. 